\title{
Analisis Video Views to Followers Ratio Tiktok Pada 5 Brand Hp Terlaris di Dunia
}

\author{
Ida Bagus Kade Ary Dwipayana \\ arydwipayana10@gmail.com
}

\begin{abstract}
TikTok is an official Chinese music video and social networking application that enlivens the digital industry in Indonesia. Tiktok allows users to create 15 -second videos accompanied by music, filters, and several other creative features. In Indonesia, there are 22.2 million active TikTok users, making Indonesia the second largest TikTok user country in the world and there are 500 million active users in the world, so the TikTok application is the largest user application in the world. In the world, there are many well-known companies that market their goods on the TikTok platform, for example, mobile phone brands. With Tik Tok and also the ease of use of the application, users can find out technological information and others. This study uses a quantitative exploratory method that is used to determine the credibility of the TikTok account performance of the 5 Best Selling Mobile Brands in the World. So that researchers get a result where the brand of one of the cellphones, namely Huawei Mobile Indonesia, gets the first rank and the brand that gets the last rank, namely Xiaomi Indonesia.
\end{abstract}

\begin{abstract}
ABSTRAK
TikTok merupakan aplikasi video musik dan jejaring sosial asal Cina resmi yang meramaikan industri digital di Indonesia. Tiktok memungkinkan penggunanya membuat video berdurasi 15 detik yang disertai dengan musik, filter, dan beberapa fitur kreatif lainnya. Di Indonesia , terdapat 22,2 juta pengguna Tiktok yang aktif sehingga menjadikan Indonesia sebagai negara pengguna TikTok terbesar kedua di dunia dan di dunia terdapat 500 juta pengguna aktif sehingga aplikasi TikTok ini menjadikan aplikasi pengguna terbanyak di dunia. Di dunia banyak perusahaan-perusahaan terkenal memasarkan barangnya di platform TikTok, contohnya seperti brand handphone. Dengan adanya Tik Tok dan juga mudahnya penggunaan aplikasi tersebut membuat pengguna dapat mengetahui informasi teknologi dan yang lainnya. Penelitian ini menggunakan sebuah metode eksploratif kuantitatif yang digunakan untuk mengetahui kredibilitas dari performa akun TikTok 5 Brand Hp Terlaris di Dunia. Sehingga peneliti mendapatkan sebuah hasil yang dimana brand salah satu hp yaitu Huawei Mobile Indonesia mendapatkan peringkat pertama dan brand yang mendapatkan peringkat terakhir yaitu Xiaomi Indonesia
\end{abstract}

Keywords : Credibility of TikTok account; TikTok Social Media ; Best Selling Mobile Brand. 


\section{PENDAHULUAN}

Perkembangan teknologi memberikan banyak manfaat bagi kehidupan manusia salah satu contohnya yaitu media sosial. Media sosial sendiri memberikan pengaruh yang sangat besar, dimana sosial media selain digunakan berkomunikasi media sosial biaa digunakan untuk memberitahu kegiatan yang sedang di lakukan. Komunikasi tidak hanya dilakukan dengan bertemu langsung, tetapi komunikasi dapat dilakukan dengan menggunakan sebuah aplikasi media sosial yang telah ada. Kelebihan media sosial yaitu dapat berinteraksi dengan orang lain yang jaraknya cukup berjauhan.

Dengan majunya perkembangan teknologi media sosial, telah memberikan dampak yang cukup besar dimana sebelumnya hanya terdapat aplikasi chatting dan email untuk berkomunikasi sekarang telah banyak munculnya jejaring media sosial yang memudahkan berkomunikasi dengan cepat. Salah satu contoh aplikasi media sosial yang terkenal ialah TikTok. Tiktok memungkinkan penggunanya membuat video berdurasi 15 detik yang disertai dengan musik, filter, dan beberapa fitur kreatif lainnya. (Adawiyah 2020).

Di Indonesia , terdapat 22,2 juta pengguna Tiktok yang aktif sehingga menjadikan Indonesia sebagai negara pengguna TikTok terbesar kedua di dunia dan di dunia terdapat 500 juta pengguna aktif sehingga aplikasi TikTok ini menjadikan aplikasi pengguna terbanyak di dunia. Banyaknya pengguna tiktok di Indonesia maupun di dunia, dapat memberikan peluang bagi brand-brand terkenal untuk memasarkan barangnya dan menjadikan platform ini sebagai platform social media marketing. Di dunia banyak perusahaan-perusahaan terkenal memasarkan barangnya di platform TikTok, contohnya seperti brand handphone atau biasa disebut hp. Adapun 5 Brand Hp Terlaris di Dunia, diantaranya yaitu : Apple, Xiaomi Indonesia, Huawei Mobile Indonesia, Samsung Indonesia, Oppo Indonesia ("5 Brand HP Terlaris Di Dunia, Siapa Juaranya__ Kumparan,” n.d.).

Penelitian ini menggunakan metode eksploratif kuantitatif, dan akan menghitung menggunakan rasio-rasio yang ada pada TikTok. Pada penelitian (I Putu Hendika Permana and Ni Putu Suci Meinarni 2021) menjelaskan bahwa terdapat 17 rasio yang ada pada sosial media TikTok dan relevan digunakan sebagai media ukur kredibilitas akun yang ada. Penelitian ini hanya berfokus untuk menghitung kredibilitas Video Views to Followers Pada 5 Brand Hp Terlaris di Dunia. Tujuan dari penelitian ini adalah mengetahui kredibilitas performa dari akun TikTok 5 Brand Hp Terlaris di Dunia menggunakan Video Views to Followers Ratio. 


\section{TINJAUAN PUSTAKA}

Di masa sekarang perkembangan teknologi sudah berjalan dengan sangat pesat. Dengan berkembangnya teknologi dan juga media sosial memudahkan manusia dalam berkomunikasi jarak jauh dengan orang lain. Pengertian media sosial atau new media merupakan media yang menawarkan digitisation, convergence, interactiviy, dan development of network terkait pembuatan pesan dan penyampaian pesannya. Kemampuanya menawarkan interaktifitas ini memungkinkan pengguna dari new media memiliki pilihan informasi apa yang dikonsumsi, sekaligus mengendalikan keluaran informasi yang dihasilkan serta melakukan pilihan-pilihan yang diinginkannya. (Watie 2016).

Aplikasi media sosial yang banyak di gemari oleh kalangan masyarakat yaitu Whatsapp, Twitter, Instagram, TikTok, Telegram dan yang lainnya. Semakin lama aplikasi-aplikasi tersebut berkembang lebih baik lagi dimana aplikasi tersebut bisa membuat candu khususnya di kalangan masyarakat. Salah satunya aplikasi media sosial yang terkenal yaitu TikTok. TikTok merupakan aplikasi video musik dan jejaring sosial asal Cina resmi yang meramaikan industri digital di Indonesia (Oktaheriyani, Wafa, and Shadiqien 2020). Aplikasi Tik Tok digunakan untuk merekam, mengedit dan mengunggah ke beberapa media sosial sehingga dapat dilihat oleh teman-teman baik sesama pengguna aplikasi Tik Tok maupun yang bukan pengguna aplikasi Tik Tok, yang membedakannya dengan media sosial lain adalah aplikasi Tik Tok memiliki berbagai macam fitur yang bisa dinikmati penggunannya seperti adanya fitur spesial effects yang terdiri dari effects shaking dan shivering yang berfungsi untuk menciptakan sebuah video yang menarik (Fauziah 2019).

Aplikasi Tiktok di salah satu platform pengunduh aplikasi yaitu Google Play Indonesia mencatat terdapat 9.031.265 pengunduh (Irwansyah 2021) dan para pengguna Tiktok ini kebanyakan berasal dari kalangan remaja serta dewasa muda (sekitar 16-24 tahun). Dimana mereka inilah salah satu audien yang bagus untuk pemasaran di Tiktok yang mana pemasaran yang sangat potensial bagi sebuah produk (Priatama et al. 2021).

Dengan adanya Tik Tok dan juga mudahnya penggunaan aplikasi tersebut membuat pengguna dapat mengetahui informasi teknologi dan yang lainnya. Sehingga dengan ketenaran aplikasi ini, membuat brand hp dengan mudah dalam memasarkan barangnya dan memikat banyak pelanggan untuk membelinya. 


\section{Metode Penelitian}

Penelitian ini menggunakan metode eksploratif kuantitatif untuk mengetahui kredibilitas dari performa akun TikTok 5 Brand Hp Terlaris di Dunia. Metode eksploratif penelitian yang berupaya memaparkan atau menggambarkan fenomena dimana peneliti belum memiliki arah atau peta penjelasan tentang fenomena yang dihadapinya (Mudjiyanto 2018).

Tujuan dari penelitian ini yaitu mengetahui nilai kredibillitas dari performa akun TikTok 5 Brand Hp Terlaris di Dunia. Ada beberapa langkah yang harus dilakukan dalam penelitian ini, sehingga mampu menemukan peringkat pertama akun TikTok Brand Hp Terlaris di Dunia yang memiliki performa terbaik. Langkah-langkah yang dilakukan pada penelitian ini, diantaranya yaitu :

\section{Melakukan Eksplorasi Pada Website Untuk Menentukan Objek yang Akan} Dianalisa.

Eksplorasi ini dilakukan pada beberapa halaman website yang menyediakan informasi mengenai objek yang akan di teliti. Setelah ekslorasi selesai dilakukan, sehingga ditemukan nama-nama Brand Hp Terlaris di Dunia yang akan dijadikan objek analisa. Setelah melakukan eksplorasi pada halaman website, maka langkah selanjutnya yaitu mencari nama akun TikTok dari masing-masing brand hp. Pastikan semua vendor memiliki akun pada aplikasi sosial media TikTok.

\section{Menghitung Nilai Rata-Rata Variable Dari 5 Brand Hp Terlaris di Dunia}

Variabel merupakan sesuatu yang memiliki nilai bervariasi dimana nilai tersebut dapat dijadikan sebagai dasar untuk empat data yang berbeda seperti rasio, skala, ordinal, nominal dan internal (Rangkuti 2015). Untuk menghitung nilai rata-rata dari variabel video views dan variabel followers yaitu dengan cara mengambil minimal 10 postingan kemudian di hitung sehingga menemukan nilai rata-rata dari masing-masing variabel.

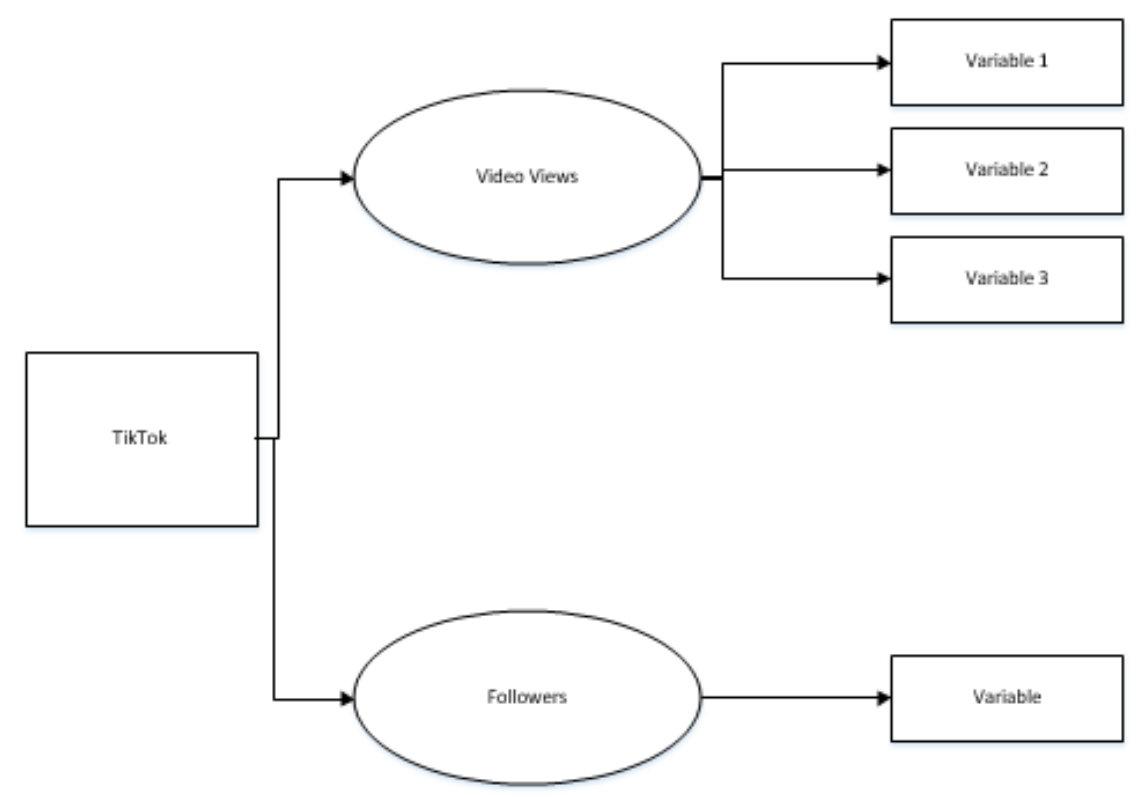

Gambar 1. Analisa Nilai Rata-Rata Variabel. 


\section{Menghitung Nilai Kredibilitas Rasio}

Untuk menghitung nilai kredibilitas dari video views to followers ratio, peneliti menggunakan cara membagi nilai variabel pertama dengan nilai variabel kedua. Jika video comments memiliki nilai 400 dan followers memiliki nilai 500, maka cara menghitungnya yaitu $400: 500=0,8$. Dengan begitu nilai dari video views to followers ratio adalah 0,8 .

\section{Menentukan Peringkat Pada Akun TikTok}

Pada langkah terakhir yang dilakukan pada penelitian ini yaitu menentukan peringkat pada masing-masing rasio yang ada. Pada penentuan peringkat perlu melihat karakteristik dari rasio yang di teliti. Jika karakteristik rasio merupakan rendah, maka objek yang memiliki nilai terendah akan mendapatkan angka 5 dan objek yang memiliki nilai tertinggi akan mendapatkan angka 1. Namun jika rasio memiliki karakteritik tinggi maka objek yang mendapatkan nilai tinggi akan mendapatkan angka 5 dan objek yang mendapatkan nilai terendah akan mendapatkan angka 1. Setelah mendapatkan hasil kredibilitas ratio maka dapat disimpulkan objek yang mana mendapatkan peringkat 1 sampai dengan peringkat 5 . 


\section{HASIL DAN PEMBAHASAN}

Akun Tiktok dari 5 Brand Hp Terlaris di Dunia, di antaranya:

\section{Apple}

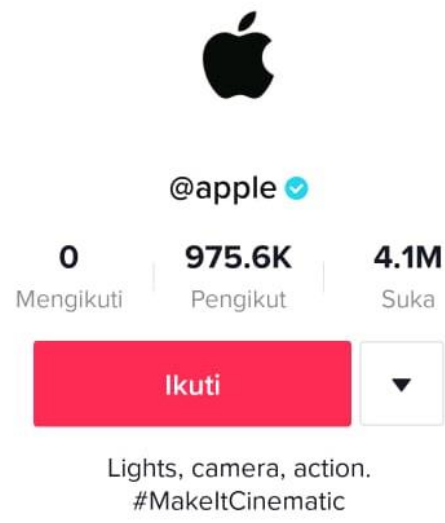

Gambar 1. Akun TikTok Apple

Sumber : https://www.tiktok.com/@apple (akses pada 21-10-2021)

\section{Xiaomi Indonesia}

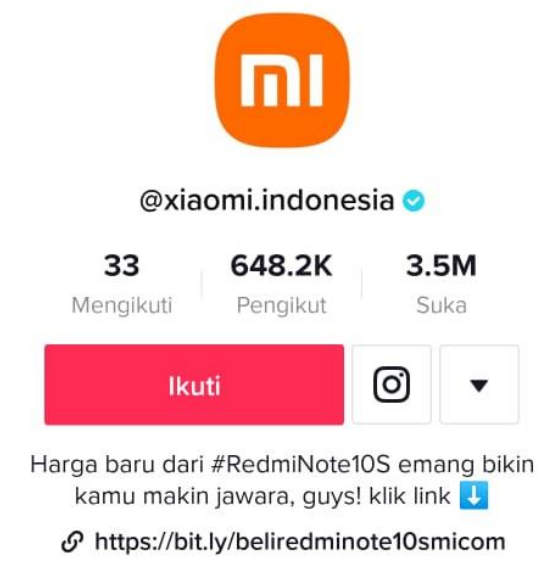

Gambar 2. Akun TikTok Xiaomi Indonesia

Sumber : https://www.tiktok.com/@xiaomi.indonesia (akses pada 21-10-2021) 


\section{Huawei Mobile Indonesia}

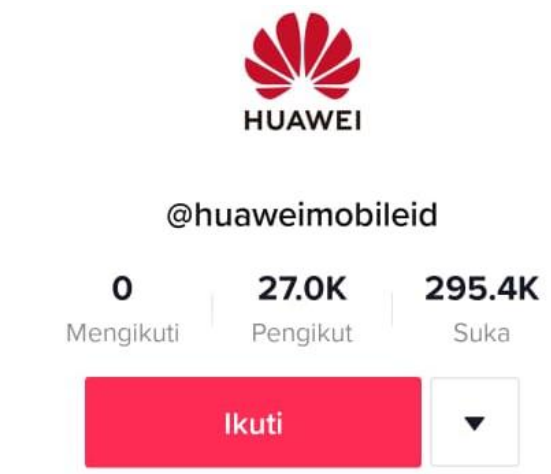

HUAWEI Mobile ID I 25 Sept 2021, 16:00 WIB Live streaming

$\odot$ http://consumer.huawei.com/id/

Gambar 3. Akun TikTok Huawei Mobile Indonesia

Sumber : https://www.tiktok.com/@ huaweimobileid (akses pada 21-10-2021)

\section{Samsung Indonesia}

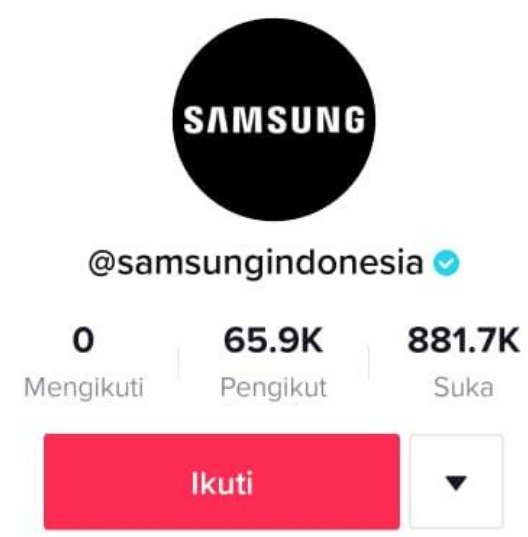

Akun TikTok resmi Samsung Indonesia

$\mathcal{O}$ https://Ink.bio/Samsunglndonesia

Gambar 4. Akun TikTok Samsung Indonesia

Sumber : https://www.tiktok.com/@samsungindonesia (akses pada 21-10-2021) 


\section{Oppo Indonesia}

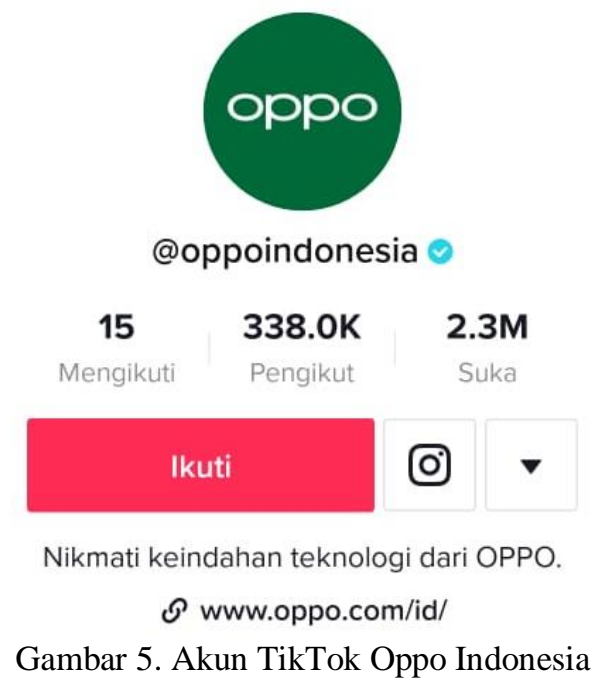

Sumber : https://www.tiktok.com/@oppoindonesia?lang=id-ID (akses pada 21-10-2021)

Dari kelima akun TikTok dari 5 brand hp terlaris di dunia, peneliti menemukan nilai dari masing-masing variabel yang ada untuk menghitung rasio Video Views to Followers dari setiap akun. Pada akun TikTok terdapat 7 variabel, diantaranya yaitu:

1. Likes

2. Followers

3. Following

4. Video Likes

5. Video Comments

6. Video Share

7. Video Views

Dari ketujuh variabel tersebut peneliti hanya fokus untuk menemukan hasil dari 2 variabel, yaitu :

1. Video Views

2. Followers

Dari kedua variable tersebut kemudian dianalisa sehingga menemukan nilai rata-rata dari variable video views dan followers. Untuk menghitung nilai rata-rata dari variable video views dan followers yaitu dengan cara mengambil 4 hingga 10 postingan video kemudian di hitung sehingga menemukan nilai rata-rata dari masing-masing variabel. Berikut merupakan tabel nilai rata-rata dari masing-masing brand hp terlaris di dunia yaitu : 
Tabel 1. Analisa Nilai Rata-Rata Nilai Variabel Video Views dan Followers Akun TikTok Apple

\begin{tabular}{|c|c|c|}
\hline No & $\begin{array}{c}\text { Video } \\
\text { Views }\end{array}$ & $\begin{array}{c}\text { Followers } \\
\text { Ratio }\end{array}$ \\
\hline 1 & 11.200 .000 & 864.000 \\
\hline 2 & 10.100 .000 & 864.000 \\
\hline 3 & 12.000 .000 & 864.000 \\
\hline 4 & 21.700 .000 & 864.000 \\
\hline Total & $\mathbf{1 3 . 7 5 0 . 0 0 0}$ & $\mathbf{8 6 4 . 0 0 0}$ \\
\hline
\end{tabular}

Sumber : Pengolah Data Excel

Tabel 2. Analisa Nilai Rata-Rata Nilai Variabel Video Views dan Followers Akun TikTok Xiaomi Indonesia

\begin{tabular}{|c|c|c|}
\hline No & $\begin{array}{c}\text { Video } \\
\text { Views }\end{array}$ & $\begin{array}{c}\text { Followers } \\
\text { Ratio }\end{array}$ \\
\hline 1 & 1.654 & 643.100 \\
\hline 2 & 144.700 & 643.100 \\
\hline 3 & 2.335 & 643.100 \\
\hline 4 & 294.300 & 643.100 \\
\hline 5 & 59.700 & 643.100 \\
\hline 6 & 2.470 & 643.100 \\
\hline 7 & 2.298 & 643.100 \\
\hline 8 & 153.500 & 643.100 \\
\hline 9 & 2.645 & 643.100 \\
\hline 10 & 2.727 & 643.100 \\
\hline Total & $\mathbf{6 6 . 6 3 3}$ & $\mathbf{6 4 3 . 1 0 0}$ \\
\hline
\end{tabular}

Sumber : Pengolah Data Excel

Tabel 3. Analisa Nilai Rata-Rata Nilai Variabel Video Views dan Followers Akun TikTok Huawei Mobile Indonesia

\begin{tabular}{|c|c|c|}
\hline No & $\begin{array}{c}\text { Video } \\
\text { Views }\end{array}$ & $\begin{array}{c}\text { Followers } \\
\text { Ratio }\end{array}$ \\
\hline 1 & 288 & 27.000 \\
\hline 2 & 477 & 27.000 \\
\hline 3 & 703 & 27.000 \\
\hline 4 & 14.200 .000 & 27.000 \\
\hline 5 & 7.400 .000 & 27.000 \\
\hline 6 & 776 & 27.000 \\
\hline 7 & 3.197 & 27.000 \\
\hline 8 & 2.118 & 27.000 \\
\hline 9 & 2.069 & 27.000 \\
\hline 10 & 1.337 & 27.000 \\
\hline Total & $\mathbf{2 . 1 6 1 . 0 9 7}$ & $\mathbf{2 7 . 0 0 0}$ \\
\hline
\end{tabular}

Sumber : Pengolah Data Excel 
Tabel 4. Analisa Nilai Rata-Rata Nilai Variabel Video Views dan Followers Akun TikTok Samsung Indonesia

\begin{tabular}{|c|c|c|}
\hline No & $\begin{array}{c}\text { Video } \\
\text { Views }\end{array}$ & $\begin{array}{c}\text { Followers } \\
\text { Ratio }\end{array}$ \\
\hline 1 & 20 & 65.200 \\
\hline 2 & 308 & 65.200 \\
\hline 3 & 673 & 65.200 \\
\hline 4 & 3.500 .000 & 65.200 \\
\hline 5 & 1.294 & 65.200 \\
\hline 6 & 2.257 & 65.200 \\
\hline 7 & 3.600 .000 & 65.200 \\
\hline 8 & 3.600 .000 & 65.200 \\
\hline 9 & 3.700 .000 & 65.200 \\
\hline 10 & 2.422 & 65.200 \\
\hline Total & $\mathbf{1 . 4 4 0 . 6 9 7}$ & $\mathbf{6 5 . 2 0 0}$ \\
\hline
\end{tabular}

Sumber : Pengolah Data Excel

Tabel 5. Analisa Nilai Rata-Rata Nilai Variabel Video Views dan Followers Akun TikTok Oppo Indonesia

\begin{tabular}{|c|r|r|}
\hline No & Video Views & $\begin{array}{c}\text { Followers } \\
\text { Ratio }\end{array}$ \\
\hline 1 & 3.242 & 334.900 \\
\hline 2 & 3.800 .000 & 334.900 \\
\hline 3 & 8.796 & 334.900 \\
\hline 4 & 14.300 & 334.900 \\
\hline 5 & 5.159 & 334.900 \\
\hline 6 & 10.100 & 334.900 \\
\hline 7 & 7.364 & 334.900 \\
\hline 8 & 10.500 & 334.900 \\
\hline 9 & 2.300 .000 & 334.900 \\
\hline 10 & 2.300 .000 & 334.900 \\
\hline Total & $\mathbf{8 4 5 . 9 4 6}$ & $\mathbf{3 3 4 . 9 0 0}$ \\
\hline \multicolumn{2}{|c|}{ Sumber $:$ Pengolah Data Excel } \\
\hline
\end{tabular}


Setelah menghitung nilai rata-rata tersebut, maka akan mendapatkan hasil akhir nilai rata-rata dari variable video views to followers.

Tabel 6. Nilai Variabel Pada 5 Akun TikTok Brand Hp Terlaris di Dunia

\begin{tabular}{|c|c|c|c|c|c|}
\hline \multicolumn{7}{|c|}{ Tabel Nilai Masing-Masing Variabel } \\
\hline Variable & Apple & $\begin{array}{c}\text { Samsung } \\
\text { Indonesia }\end{array}$ & $\begin{array}{c}\text { Xiaomi } \\
\text { Indonesia }\end{array}$ & $\begin{array}{c}\text { Oppo } \\
\text { Indonesia }\end{array}$ & $\begin{array}{c}\text { Huawei Mobile } \\
\text { Indonesia }\end{array}$ \\
\hline Followers & 864000 & 65200 & 643100 & 334900 & 27000 \\
\hline $\begin{array}{c}\text { Video } \\
\text { Views }\end{array}$ & 13750000 & 1440697 & 66633 & 845946 & 2161097 \\
\hline
\end{tabular}

Sumber : Pengolah Data Excel

Pada akun TikTok terdapat 17 rasio yang relevan digunakan untuk mengukur kredibilitas pada masing-masing akun. Namun pada penelitian kali ini hanya berfokus untuk menghitung Video Views to Followers. Untuk menghitung kredibilitas dari masing-masing akun TikTok setiap brand hp, peneliti menghitung dengan cara : variabel 2 akan dibagi dengan variabel 1, sehingga ditemukan hasil analisisa dari rasio tersebut.

Tabel 7. Hasil Perhitungan Rasio Akun TikTok Brand Hp Terlaris di Dunia

\begin{tabular}{|c|c|c|c|c|c|c|}
\hline NO & Ratio & Apple & $\begin{array}{c}\text { Samsung } \\
\text { Indonesia }\end{array}$ & $\begin{array}{c}\text { Xiaomi } \\
\text { Indonesia }\end{array}$ & Oppo & $\begin{array}{c}\text { Huawei } \\
\text { Mobile } \\
\text { Indonesia }\end{array}$ \\
\hline 1 & $\begin{array}{c}\text { Video } \\
\text { Views to } \\
\text { Followers } \\
\text { Ratio }\end{array}$ & 15,91435185 & 22,09657975 & 0,103612191 & 2,52596596 & 80,04062963 \\
\hline
\end{tabular}

Sumber : Pengolah Data Excel

Video Views to Followers Ratio memiliki karakteristik yang tinggi, artinya semakin tinggi nilai yang dihasilkan maka semakin baik kredibilitas dari performa akun tersebut. Untuk memberikan peringkat pada masing-masing brand hp, peneliti memberikan angka 5 kepada brand yang mendapatkan nilai tertinggi dan angka 1 untuk brand hp yang mendapatkan nilai terendah. Berikut merupakan tabel urutan nilai yang dihasilkan oleh masing-masing brand hp. 
Tabel 8. Nilai Rasio Akun TikTok Brand Hp Terlaris di Dunia

\begin{tabular}{|c|c|c|c|c|}
\hline Apple & $\begin{array}{c}\text { Samsung } \\
\text { Indonesia }\end{array}$ & $\begin{array}{c}\text { Xiaomi } \\
\text { Indonesia }\end{array}$ & Oppo Indonesia & $\begin{array}{c}\text { Huawei Mobile } \\
\text { Indonesia }\end{array}$ \\
\hline 3 & 4 & 1 & 2 & 5 \\
\hline
\end{tabular}

Dari Tabel Nilai Rasio Akun TikTok 5 Brand Hp Terlaris di Dunia dapat di simpulkan bahwa Huawei Mobile Indonesia mendapatkan nilai tertinggi untuk rasio Video Views to Followers. Sedangkan akun TikTok Xaomi Indonesia mendapatkan nilai terendah untuk rasio ini. Jadi, pada penelitian ini Huawei Mobile Indonesia memiliki kredibilitas performa yang lebih baik dibandingkan dengan brand hp yang lainnya. 


\section{KESIMPULAN}

Tujuan dari penelitian ini adalah mengetahui kredibilitas performa dari akun TikTok 5 Brand Hp Terlaris di Dunia menggunakan Video Views to Followers Ratio. Top 5 Brand Hp tersebut diantaranya : Apple, Samsung Indonesia, Xiaomi Indonesia, Oppo Indonesia, dan Huawei Mobile Indonesia. Dari kelima brand hp tersebut dapat disimpulkan bahwa :

1. Peringkat pertama diraih oleh brand Huawei Mobile Indonesia dengan nilai tertinggi yaitu 80,04062963

2. Peringkat kedua diraih oleh brand Samsung Indonesia dengan nilai yaitu 22,09657975

3. Peringkat ketiga diraih oleh brand Apple dengan nilai yaitu 15,91435185

4. Peringkat keempat diraih oleh brand Oppo Indonesia dengan nilai yaitu 2,52596596

5. Peringkat kelima diraih oleh brand Xiaomi Indonesia dengan nilai terendah yaitu 0,103612191 


\section{DAFTAR PUSTAKA}

"5 Brand HP Terlaris Di Dunia, Siapa Juaranya_ Kumparan.” n.d. https://kumparan.com/kumparantech/5-brand-hp-terlaris-di-dunia-siapa-juaranya$1 \mathrm{v} 46 \mathrm{FoYjCPi}$.

Adawiyah, Dwi Putri Robiatul. 2020. "Pengaruh Penggunaan Aplikasi TikTok Terhadap Kepercayaan Diri Remaja Di Kabupaten Sampang.” Jurnal Komunikasi 14 (2): 135-48. https://doi.org/10.21107/ilkom.v14i2.7504.

Fauziah, Yuliani Resti. 2019. "Konsep Diri Remaja Pengguna Aplikasi Tik Tok Di Kota Bandung.” Jurnal Ilmu Komunikasi, no. 112: 1-2.

I Putu Hendika Permana, and Ni Putu Suci Meinarni. 2021. "Ratio Analysis on Tiktok (Social Media) for Qualitative Research Using Explorative Methods." Jurnal Ekonomi \& Bisnis JAGADITHA 8 (1): 30-38. https://doi.org/10.22225/jj.8.1.2944.30-38.

Irwansyah. 2021. "Tiktok, Instrumen Media Sosial Baru Dalam Politik." Mediaindonesia.Com. https://mediaindonesia.com/opini/387394/tiktok-instrumenmedia-sosial-baru-dalam-politik.

Mudjiyanto, Bambang. 2018. "Tipe Penelitian Eksploratif Komunikasi." Jurnal Studi Komunikasi Dan Media 22 (1): 65. https://doi.org/10.31445/jskm.2018.220105.

Oktaheriyani, Desy, M Ali Wafa, and Shen Shadiqien. 2020. "Analisis Perilaku Komunikasi Pengguna Media Sosial TikTok (Studi Pada Mahasiswa Fakultas Ilmu Sosial Dan Ilmu Politik UNISKA MAB Banjarmasin ).” Jurnal Ilmu Sosial Dan Ilmu Politik, 7-52. http://eprints.uniska-bjm.ac.id/id/eprint/3504.

Priatama, Ryan, Ilham Hilal Ramadhan, Az- Zuhaida, Awanis Akalili, and Febriansyah Kulau. 2021. "ANALISIS TEKNIK DIGITAL MARKETING PADA APLIKASI TIKTOK (Studi Kasus Akun TikTok @jogjafoodhunterofficial).” SOCIA: Jurnal IlmuIlmu Sosial 18 (1): 49-60. https://doi.org/10.21831/socia.v18i1.40467.

Rangkuti, Freddy. 2015. "Riset Pemasaran - Google Buku."

https://books.google.co.id/books?hl=id\&lr=\&id=CdE7MiKx8_kC\&oi=fnd\&pg=PR21\& $\mathrm{dq}=$ dampak+tidak+ada++riset + pasar\&ots $=3 \mathrm{Mpj0Q0nYg \& sig=hVXCejpo4qm2B84Yw}$ $\mathrm{Zp}-\mathrm{w} 88 \mathrm{oJJ}$ o\&redir_esc=y\#v=onepage \&q\&f=false.

Watie, Errika Dwi Setya. 2016. "Komunikasi Dan Media Sosial (Communications and Social Media)." Jurnal The Messenger 3 (2): 69.

https://doi.org/10.26623/themessenger.v3i2.270. 